\title{
Interdepartmental program to improve outcomes for acute heart failure patients seen in the emergency department
}

\author{
Ian G. Stiell ${ }^{1,5} \cdot$ Lisa Mielniczuk ${ }^{2} \cdot$ Heather D. Clark ${ }^{3} \cdot$ Guy Hebert $^{1} \cdot$ Monica Taljaard $^{4,5} \cdot$ Alan J. Forster $^{5} \cdot$ \\ George A. Wells $5^{5,6}$. Catherine M. Clement ${ }^{5}$. Jennifer Brinkhurst ${ }^{5}$. Erica L. Brown ${ }^{5}$. Marie-Joe Nemnom ${ }^{5}$. \\ Jeffrey J. Perry ${ }^{1,5}$
}

Received: 11 May 2020 / Accepted: 23 October 2020 / Published online: 4 January 2021

(c) Canadian Association of Emergency Physicians (CAEP)/ Association Canadienne de Médecine d'Urgence (ACMU) 2021

\begin{abstract}
Introduction Acute heart failure patients often have an uncertain or delayed follow-up after discharge from the ED. Our goal was to introduce rapid-access specialty clinics to ensure acute heart failure patients were seen within 7 days, in an effort to reduce admissions and improve follow-up care.

Methods This prospective cohort study was conducted at two campuses of a large tertiary care hospital. We enrolled acute heart failure patients who presented to the ED with shortness of breath and were later discharged. Following a 12-month before period, we introduced rapid-access acute heart failure clinics staffed by cardiology and internal medicine. We allowed for a 3-month implementation period and then observed outcomes over the subsequent 12-month after period. The primary outcome was hospital admission within 30 days. Secondary outcomes included mortality and actual access to specialty care. Results Patients in the before $(N=355)$ and after periods $(N=374)$ were similar for age and most characteristics. Segmented autoregression analysis demonstrated there was a pre-existing trend to fewer admissions. Attendance at a specialty clinic increased from 17.8 to $42.1 \%(P<0.01)$ and the median days to the clinic decreased from 13 to 6 days $(P<0.01)$. 30-days mortality did not change.

Conclusion Implementation of rapid-access clinics for acute heart failure patients discharged from the ED did not lead to an overall decrease in hospital admissions. It did, however, lead to increased access to specialist care, reduced follow-up times, without an increase in return ED visits or mortality. Widespread use of this rapid-access approach to a specialist can improve care for acute heart failure patients discharged home from the ED.
\end{abstract}

Keywords Heart failure $\cdot$ Emergency department $\cdot$ Patient safety

Electronic supplementary material The online version of this article (https://doi.org/10.1007/s43678-020-00047-x) contains supplementary material, which is available to authorized users.

Ian G. Stiell

istiell@ohri.ca

1 Department of Emergency Medicine, University of Ottawa, Ottawa, ON, Canada

2 Division of Cardiology, University of Ottawa Heart Institute, University of Ottawa, Ottawa, ON, Canada

3 Division of Internal Medicine, Department of Medicine, University of Ottawa, Ottawa, ON, Canada
4 Clinical Epidemiology Program, School of Epidemiology and Public Health, University of Ottawa, Ottawa, ON, Canada

5 Clinical Epidemiology Program, Ottawa Hospital Research Institute, Ottawa, ON, Canada

6 University of Ottawa Heart Institute, University of Ottawa, Ottawa, ON, Canada 


\section{Résumé}

Introduction Les patients atteints d'insuffisance cardiaque aiguë ont souvent un suivi incertain ou retardé après leur sortie de l'urgence. Notre objectif était de mettre en place des cliniques spécialisées à accès rapide pour veiller à ce que les patients de d'insuffisance cardiaque aiguë soient vus dans les sept jours, afin de réduire les admissions et d'améliorer les soins de suivi. Méthodes Cette étude de cohorte prospective a été menée sur deux campus d'un grand hôpital de soins tertiaires. Nous avons recruté des patients atteints de d'insuffisance cardiaque aiguë qui se sont présentés aux urgences avec un essoufflement et qui ont ensuite été renvoyés chez eux. Après une période antérieure de 12 mois, nous avons mis en place des cliniques de d'insuffisance cardiaque aiguë à accès rapide dotées de personnel en cardiologie et en médecine interne. Nous avons prévu une période de mise en œuvre de 3 mois et avons ensuite observé les résultats au cours des 12 mois suivants. Le résultat principal était l'admission à l'hôpital dans les 30 jours. Les résultats secondaires comprenaient la mortalité et l'accès réel aux soins spécialisés.

Résultats Les patients des périodes avant $(\mathrm{N}=355)$ et après $(\mathrm{N}=374)$ étaient similaires pour l'âge et la plupart des caractéristiques. Une analyse d'autorégression segmentée a démontré qu'il y avait une tendance préexistante à moins d'admissions. La fréquentation d'une clinique spécialisée est passée de $17,8 \%$ à $42,1 \%(\mathrm{P}<0,01)$ et les jours médians à la clinique ont diminué de 13 à 6 jours $(\mathrm{P}<0,01)$. La mortalité à 30 jours n'a pas changé.

Conclusion La mise en place de cliniques à accès rapide pour les patients d'insuffisance cardiaque aiguë sortant de l'urgence n'a pas entraîné une diminution globale des admissions à l'hôpital Elle a toutefois permis d'améliorer l'accès aux soins spécialisés et de réduire les délais de suivi, sans pour autant augmenter les visites de retour aux urgences ou la mortalité. L'utilisation généralisée de cette approche d'accès rapide à un spécialiste peut améliorer les soins pour les patients atteints de d'insuffisance cardiaque aiguë renvoyés chez eux par les services d'urgence.

\section{Clinician's capsule}

\section{What is known about the topic?}

For acute heart failure patients discharged from the ED, early follow-up is often not available, and some will have poor outcomes.

\section{What did this study ask?}

We evaluated the impact of rapid-access specialty clinics that saw acute heart failure patients discharged from the ED within 7 days.

\section{What did this study find?}

The acute heart failure clinics increased access to specialist care and reduced follow-up times, without increasing return ED visits or mortality.

Why does this study matter to clinicians?

Widespread use of this rapid-access approach to specialist may improve care for the many acute heart failure patients discharged home from the ED.

\section{Introduction}

100,000 patients with a sudden increase of shortness of breath due to acute heart failure present to Canadian emergency departments (ED) each year for treatment. Acute heart failure is a common and serious condition that frequently results in morbidity and death and is a leading cause for hospital admissions for seniors [1-4].
An important challenge facing physicians when treating acute heart failure patients in the ED is deciding upon disposition, whether to admit or discharge, with or without early follow-up. It is not efficient to admit all patients as many will respond to therapy in the ED and will not benefit from hospitalization. Even so, many admitted acute heart failure patients naturally go on to have shortterm serious outcomes, i.e. they die, require intensive care therapy, or suffer myocardial infarction. In addition, some patients discharged from the ED after treatment die or relapse back to the ED and require admission. Admission decisions are important because there is frequently a shortage of available beds in Canadian hospitals and many EDs are overcrowded. We previously documented that less than $50 \%$ of acute heart failure patients seen in Canadian EDs were admitted to hospital and that one in ten of those not admitted suffered short-term serious outcomes [5, 6].

To ensure safe care for acute heart failure patients who are discharged from the ED, we must develop appropriate follow-up strategies. Patients may experience a recurrence of their symptoms or develop electrolyte abnormalities or renal impairment due to diuretic use, and close medical oversight is required. There may be a need to investigate the cause of acute heart failure to institute therapies such as revascularization in the case of ischemic heart disease. Research by others demonstrates variable but often beneficial impact of close follow-up [7-16]. Unfortunately, follow-up by family or specialty physicians is often uncertain or delayed for acute heart failure patients in many parts of Canada. Creating new rapid access specialty clinics that 
are specifically built requires careful evaluation to justify the expense and determine optimal clinic capacity.

The overall goal of our interdepartmental project was to improve safety and care for acute heart failure patients seen in the ED. We chose to introduce rapid-access specialty clinics to be managed by medicine and cardiology to ensure acute heart failure patients were seen within a few days of ED discharge. We hypothesized that comparing the before to the after periods, we would see a decrease both in initial admissions as well as in return visit admissions, without an increase in mortality or morbidity.

\section{Methods}

\section{Design and setting}

There were three study periods in this prospective cohort project. The before period (12 months) served as the control period prior to implementation; data were collected retrospectively by health records review. The implementation period (3 months) was the stage when the new referral processes were put in place and the clinics established. The after period (12 months) was the time when we prospectively enrolled patients and evaluated the impact of the interventions. This study was conducted at The Ottawa Hospital, a large tertiary care institution with two EDs, whose annual census was 175,000 visits.

\section{Study population}

We included patients $\geq 50$ years of age who presented with shortness of breath (of less than 7 days duration) due to acute heart failure and were stable enough to be considered for discharge by the attending ED physician. We included patients with acute shortness of breath secondary to an exacerbation of chronic heart failure or new-onset heart failure, using the criteria of the European Society of Cardiology [2]. This was the same patient definition previously used in two large multicentre heart failure studies [5, 6]. To be eligible, patients had to have appropriate symptoms (shortness of breath or fatigue) with clinical signs of fluid retention (pulmonary or peripheral) in the presence of an underlying abnormality of cardiac structure or function. In instances where doubt remained, a beneficial response to treatment (e.g., a brisk diuresis accompanied by improvement in breathlessness) was considered. We did not use NT-proBNP measurements as most Canadian EDs do not have access to this test and same day echocardiology is rarely available. We excluded patients who did not fit the definition of acute heart failure or who were clearly too ill to be considered for discharge after 2-12 h of ED management (exclusion criteria in Appendix) No patients who were discharged home were excluded.
The study was approved as minimal risk requiring no informed consent by the Ottawa Hospital Research Ethics Board.

\section{Interventions}

We met with internal medicine and cardiology colleagues to discuss patient eligibility and procedures to access the new rapid-access processes. Internal medicine allotted special availability with a view to seeing acute heart failure patients from the ED within $72 \mathrm{~h}$. This would accommodate patients discharged by the ED physician or internal medicine consultants. If patients were already followed by a hospital cardiologist, they could be referred to the University of Ottawa Heart Institute Heart Failure Clinic. Such direct referral from the ED had not been previously available. Both clinics were staffed by nurses and specialist physicians. Internal medicine physicians saw the patients $1-3$ times and then returned patients to their family doctor and referred complex and severe cases to the Heart Institute Clinic. We educated ED physicians and residents on the new referral process by means of face-to-face interactions, email, and social media messaging. Messaging also went out to internal medicine and cardiology physicians. Rapidity of follow-up was monitored for all patients and, where necessary, reminders of the target visit times were reviewed with clinic staff and physicians. Disposition decisions, as is usual in Canadian EDs, were jointly made by the ED physician and the patient and sometimes by the consulting services.

\section{Outcome measures}

The primary outcome measure was hospital admission within 30 days of the index visit, i.e. at the time of the index ED visit $o r$ in the subsequent 30 days. While the secondary outcomes were also very important, we believed that admission/re-admission to the hospital was an important metric both for the patient and for the health care system. This was measured by review of electronic health records and patient interviews.

Our secondary outcome measures were: mortality within 30 days, ED visits within 30 days, admissions within 30 days, hospital admission at the time of index visit, access to a specialist, time to see the specialist, compliance of patients in attending clinic, investigations ordered after ED discharge, medication revisions and prescriptions within 30 days, and access to family physicians.

\section{Data collection}

Our case identification and review process were conducted by three full-time study coordinators who each had 
5-10 years experience in collecting data during our prior multicentre heart failure studies. Potential cases in both phases of the study were identified from a daily log that contained both the presenting complaint and the final diagnosis. All cases with these terms were reviewed for eligibility: "shortness of breath, heart failure, pulmonary edema." We determined eligibility with a careful review of ED physician notes, nursing notes, consultations and discharge summaries, as well as imaging, ecg, and laboratory results. Unclear cases were further reviewed by one of the physician investigators. These assessments were made without knowledge of any clinic follow-ups. Data were abstracted in a standardized fashion onto a formal case record form and were verified with a blinded physician where the findings were unclear.

\section{Statistical analysis}

We presented patient characteristics and outcomes descriptively using frequency with proportion for categorical variables and mean with standard deviation (SD) or median with interquartile range (IQR) for continuous and ordinal variables, as appropriate.

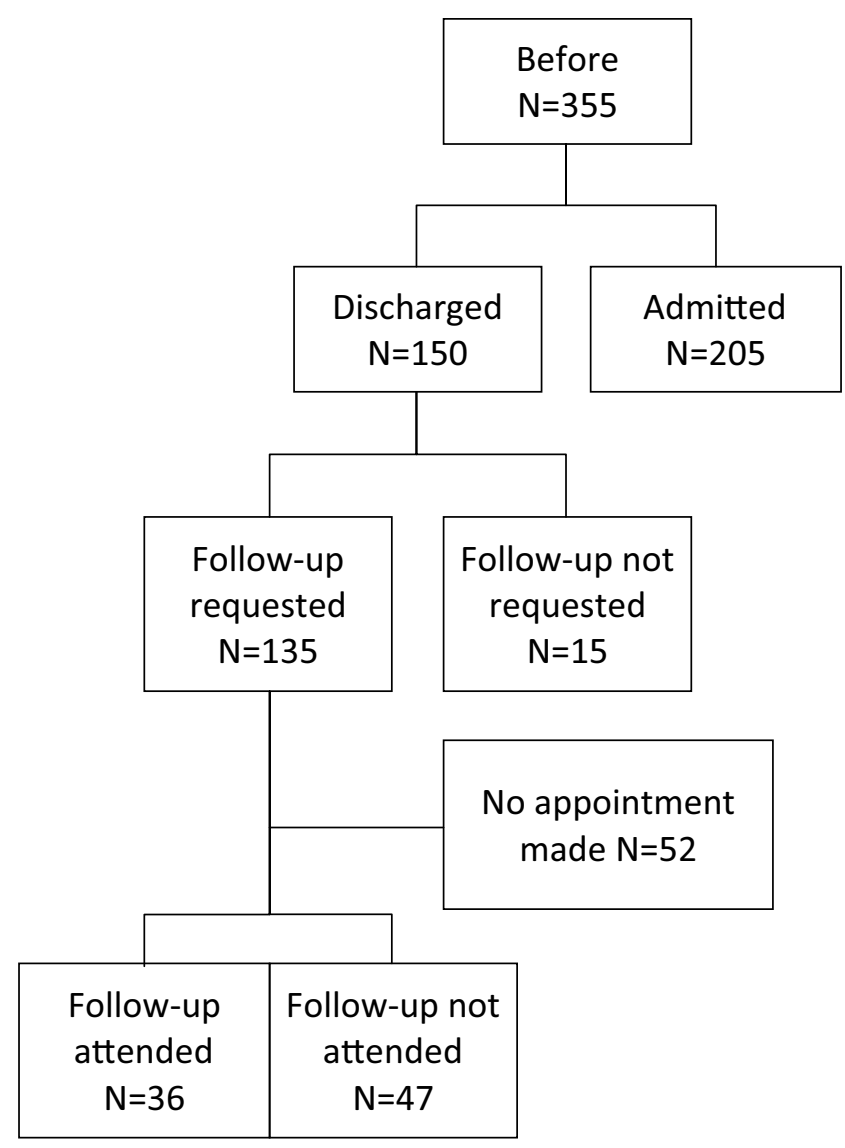

To evaluate the effect of the intervention on the primary outcome (admissions), while controlling for pre-existing trends as well as changes in patient characteristics over time, we used segmented logistic autoregression analysis of the monthly admissions. We adjusted for patient age, sex, creatinine values, history of valvular heart disease, and treatment in the ED with IV diuretics and non-invasive ventilation. The segmented regression model included coefficients representing the pre-intervention level and slope, and interruptions in the level and slope corresponding with the timing of the intervention. We hypothesized that there would be a 4-months delay from the time of introduction of the intervention in July 2017, before its effect could be fully observed. We accommodated this transition period in the analysis by omitting admission rates from that period. The outcome at the end of the study (i.e. October 2018) was compared to forecasts that used the pre-intervention trend only, i.e. the counterfactual proportion had the intervention not been introduced. We chose an interrupted time series approach over a simple before and after comparison, to avoid confounding any pre-existing trends in admissions with the effect of the clinic.

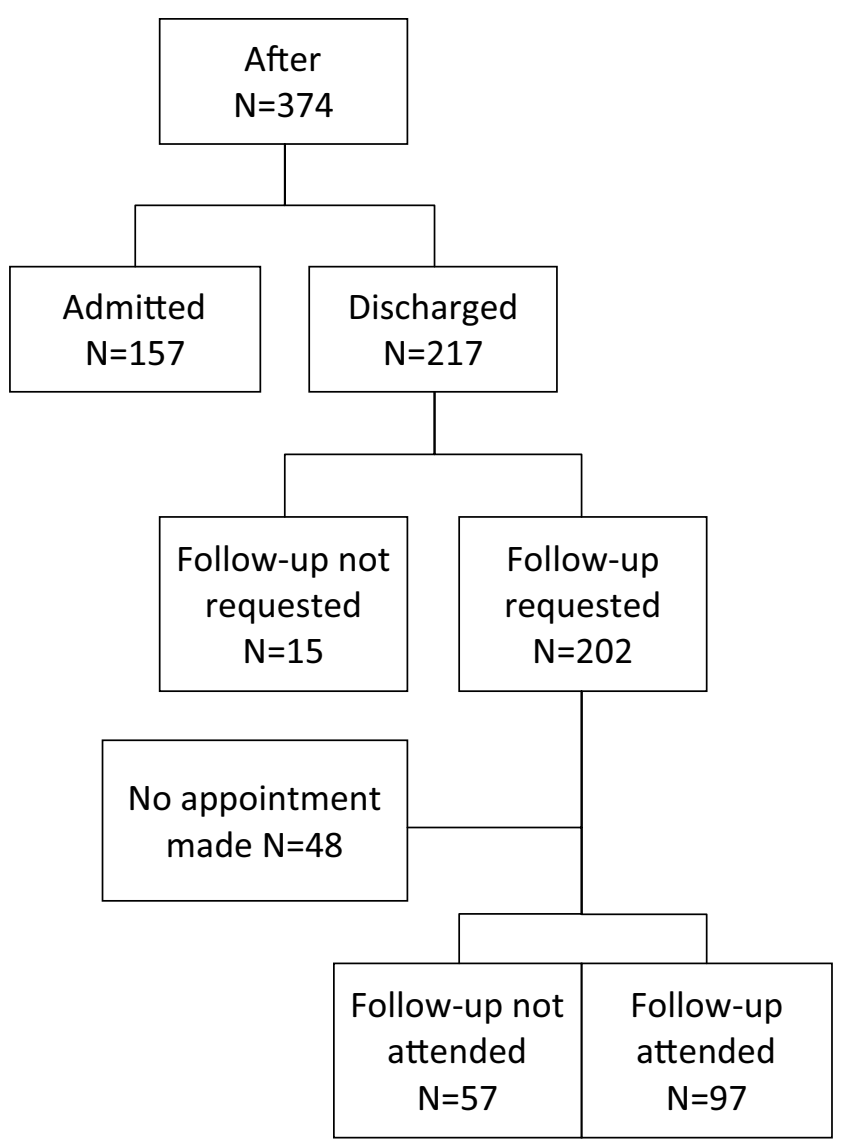

Fig. 1 Patient flowchart 
For secondary outcomes that were not amenable to segmented regression analysis, we presented differences in proportions with $95 \%$ confidence intervals (CI) to compare outcomes in the before and after groups. Rather than estimating the required sample size based on formal power calculations, our sample size was determined by the available number of patients over the 12-months before and after periods.
Table 1 Patient characteristics in the before and after periods

\begin{tabular}{|c|c|c|c|}
\hline & $\begin{array}{l}\text { Before } \\
N=355\end{array}$ & $\begin{array}{l}\text { After } \\
N=374\end{array}$ & $P$ value $^{+}$ \\
\hline Age, years (Mean, SD) & $77.8(11.0)$ & $78.1(11.2)$ & $0.70^{\wedge}$ \\
\hline Range & $50-102$ & $51-103$ & \\
\hline Male $(\%)$ & $163(45.9)$ & $207(55.3)$ & 0.01 \\
\hline \multicolumn{4}{|l|}{ Hospital site (\%) } \\
\hline Ottawa Hospital-Civic Campus & $218(61.4)$ & $209(55.9)$ & 0.13 \\
\hline Ottawa Hospital—General Campus & $137(38.6)$ & $165(44.1)$ & \\
\hline \multicolumn{4}{|l|}{ Arrival status } \\
\hline Arrival by ambulance (\%) & $173(48.7)$ & $191(51.1)$ & 0.53 \\
\hline Duration of respiratory distress, $\mathrm{h}$ (Mean, SD) & $63.2(56.8)$ & $74.1(60.9)$ & $0.01^{\wedge}$ \\
\hline Heart rate (Mean, SD) & $85.9(20.6)$ & $85.7(22.5)$ & $0.91^{\wedge}$ \\
\hline Systolic blood pressure (Mean, SD) & $142.2(27.5)$ & $141.9(28.1)$ & $0.89^{\wedge}$ \\
\hline $\mathrm{SaO} 2$ by oximetry (Mean, SD) & $93.8(5.8)$ & $95(4.7)$ & $<0.01^{\wedge}$ \\
\hline Canadian Triage Acuity Scale (CTAS) (Median, IQR) & $2(2-3)$ & $2(2-3)$ & $0.55^{\#}$ \\
\hline \multicolumn{4}{|l|}{ Past medical history (\%) } \\
\hline Hypertension & $275(77.5)$ & $282(75.4)$ & 0.51 \\
\hline Heart failure & $254(71.5)$ & $257(68.7)$ & 0.40 \\
\hline Coronary artery disease & $182(51.3)$ & $193(51.6)$ & 0.93 \\
\hline Diabetes mellitus & $164(46.2)$ & $164(43.9)$ & 0.52 \\
\hline Current or former smoker & $138(38.9)$ & $150(40.1)$ & 0.73 \\
\hline Permanent atrial fibrillation & $124(34.9)$ & $137(36.6)$ & 0.63 \\
\hline Valvular heart disease & $113(31.8)$ & $95(25.4)$ & 0.05 \\
\hline \multicolumn{4}{|l|}{ ED treatment $(\%)$} \\
\hline IV diuretics & $317(89.3)$ & $356(95.2)$ & $<0.01$ \\
\hline PO diuretic & $27(7.6)$ & $13(3.5)$ & 0.01 \\
\hline SL nitrates & $25(7.0)$ & $19(5.1)$ & 0.27 \\
\hline IV nitrates & $24(6.8)$ & $9(2.4)$ & $<0.01$ \\
\hline Non-invasive ventilation & $37(10.4)$ & $25(6.7)$ & 0.07 \\
\hline Intubation & $0(0.0)$ & $1(0.3)$ & $0.43^{\S}$ \\
\hline \multicolumn{4}{|l|}{ Discharge medications (\%) } \\
\hline Diuretic & $116(32.7)$ & $177(47.3)$ & $<0.01$ \\
\hline New prescription & $53(14.9)$ & $79(21.1)$ & \\
\hline Dose change & $63(17.7)$ & $98(26.2)$ & \\
\hline \multicolumn{4}{|l|}{ Details of admitted patients $(N=205: 157)$} \\
\hline Short-term serious outcomes* & $11(5.4)$ & $11(7.0)$ & 0.52 \\
\hline Intubation required & $0(0)$ & $1(0.6)$ & $0.43^{\S}$ \\
\hline Death before discharge & $7(3.4)$ & $5(3.2)$ & 0.90 \\
\hline Death within 30 days & $11(5.4)$ & $11(7.0)$ & 0.49 \\
\hline \multicolumn{4}{|l|}{ Short-term serious outcomes } \\
\hline Admitted to Hospital on Index ED Visit & $205(57.7)$ & $157(42.0)$ & $<0.01$ \\
\hline Death within 30 days for all patients & $16(4.5)$ & $15(4.0)$ & 0.76 \\
\hline Total admissions within 30 days & $231(65.1)$ & $200(53.5)$ & $<0.01$ \\
\hline
\end{tabular}

${ }^{*}$ Some patients may have had more than one short-term serious outcomes; ${ }^{+}$chi-square test unless otherwise noted; ${ }^{\wedge} t$ test; ${ }^{\#}$ Wilcoxon test; ${ }^{\S}$ Fisher's exact test 


\section{Results}

Figure 1 demonstrates the patients enrolled in the before and after phases of the study. In the before period, 150 (42\%) patients were discharged and, of those, $15(10 \%)$ had no follow-up requested, 52 (35\%) had no appointment made, 47 (31\%) did not follow up at the hospital, and 36 (24\%) did. In the after period, $217 / 374$ (58\%) patients were discharged from the ED. Of those, 15 (7\%) had no follow-up requested, 48 (22\%) had no hospital appointment made, 57 (26\%) did not attend an appointment, and 97 (45\%) did attend.

Table 1 shows the demographic and clinical characteristics of the 355 patients seen in the before phase, and the 374 patients seen in the after phase. There were no missing data. The table demonstrates the similarity in patient characteristics between the before and after phases. Without accounting for any secular trends and changes in patient characteristics, we observed a decrease in admission to
Table 2 Discharged patien characteristics in the before and after periods

\begin{tabular}{|c|c|c|c|}
\hline & $\begin{array}{l}\text { Before } \\
N=150\end{array}$ & $\begin{array}{l}\text { After } \\
N=217\end{array}$ & $P$ value $^{+}$ \\
\hline Age, years (Mean, SD) & $77.3(11.1)$ & $78.2(10.8)$ & $0.41^{\wedge}$ \\
\hline Range & $50-102$ & $51-103$ & \\
\hline Male $(\%)$ & $80(53.3)$ & $118(54.4)$ & 0.84 \\
\hline \multicolumn{4}{|l|}{ Hospital site (\%) } \\
\hline Ottawa Hospital—Civic Campus & $101(67.3)$ & $124(57.1)$ & 0.05 \\
\hline Ottawa Hospital—General Campus & $49(32.7)$ & $93(42.9)$ & \\
\hline \multicolumn{4}{|l|}{ Arrival status } \\
\hline Arrival by ambulance (\%) & $51(34.0)$ & $89(41.0)$ & 0.17 \\
\hline Duration of respiratory distress, $\mathrm{h}$ (Mean, SD) & $36.1(0.8)$ & $36.3(0.7)$ & $0.02^{\wedge}$ \\
\hline Heart rate (Mean, SD) & $83.7(18.5)$ & $82.2(19.1)$ & $0.46^{\wedge}$ \\
\hline Systolic blood pressure (Mean, SD) & $141.1(26.9)$ & $142.8(26.8)$ & $0.55^{\wedge}$ \\
\hline $\mathrm{SaO} 2$ by oximetry (Mean, $\mathrm{SD})$ & $95.2(4.6)$ & $95.9(3.4)$ & $0.10^{\wedge}$ \\
\hline Canadian Triage Acuity Scale (CTAS) (Median, IQR) & $3(2-3)$ & $2(2-3)$ & $0.52^{\#}$ \\
\hline \multicolumn{4}{|l|}{ Past medical history (\%) } \\
\hline Hypertension & $111(74.0)$ & $158(72.8)$ & 0.80 \\
\hline Heart failure & $106(70.7)$ & $139(64.1)$ & 0.19 \\
\hline Coronary artery disease & $74(49.3)$ & $117(53.9)$ & 0.39 \\
\hline Diabetes mellitus & $62(41.3)$ & $88(40.6)$ & 0.88 \\
\hline Current or former smoker & $42(28.0)$ & $65(30.0)$ & 0.69 \\
\hline Permanent atrial fibrillation & $55(36.7)$ & $65(30.0)$ & 0.18 \\
\hline Valvular heart disease & $39(26.0)$ & $49(22.6)$ & 0.45 \\
\hline \multicolumn{4}{|l|}{ ED treatment $(\%)$} \\
\hline IV diuretics & $130(86.7)$ & $202(93.1)$ & 0.04 \\
\hline PO diuretic & $16(10.7)$ & $11(5.1)$ & 0.04 \\
\hline SL nitrates & $5(3.3)$ & $8(3.7)$ & 0.86 \\
\hline IV nitrates & $2(1.3)$ & $1(0.5)$ & $0.57^{\S}$ \\
\hline Non-invasive ventilation & $5(3.3)$ & $5(2.3)$ & $0.75^{\S}$ \\
\hline Intubation required & $0(0.0)$ & $0(0.0)$ & - \\
\hline \multicolumn{4}{|l|}{ Discharge medications (\%) } \\
\hline Diuretic & $116(77.3)$ & $177(81.6)$ & 0.31 \\
\hline New prescription & $53(35.3)$ & $79(36.4)$ & \\
\hline Dose change & $63(42.0)$ & $98(45.2)$ & \\
\hline Short-term serious outcomes* & $26(17.3)$ & $46(21.2)$ & 0.36 \\
\hline Admission upon return to ED & $26(17.3)$ & $43(19.8)$ & 0.55 \\
\hline Death within 30 days & $5(3.3)$ & $4(1.8)$ & $0.50^{\S}$ \\
\hline Relapsed and returned to ED within 30 days & $48(32.0)$ & $63(29.0)$ & 0.54 \\
\hline
\end{tabular}

*Some patients may have had more than one short-term serious outcomes; ${ }^{+}$chi-square test unless otherwise noted; ${ }^{\text {t}}$-test; ${ }^{\#}$ Wilcoxon test; ${ }^{\S}$ Fisher's exact test 


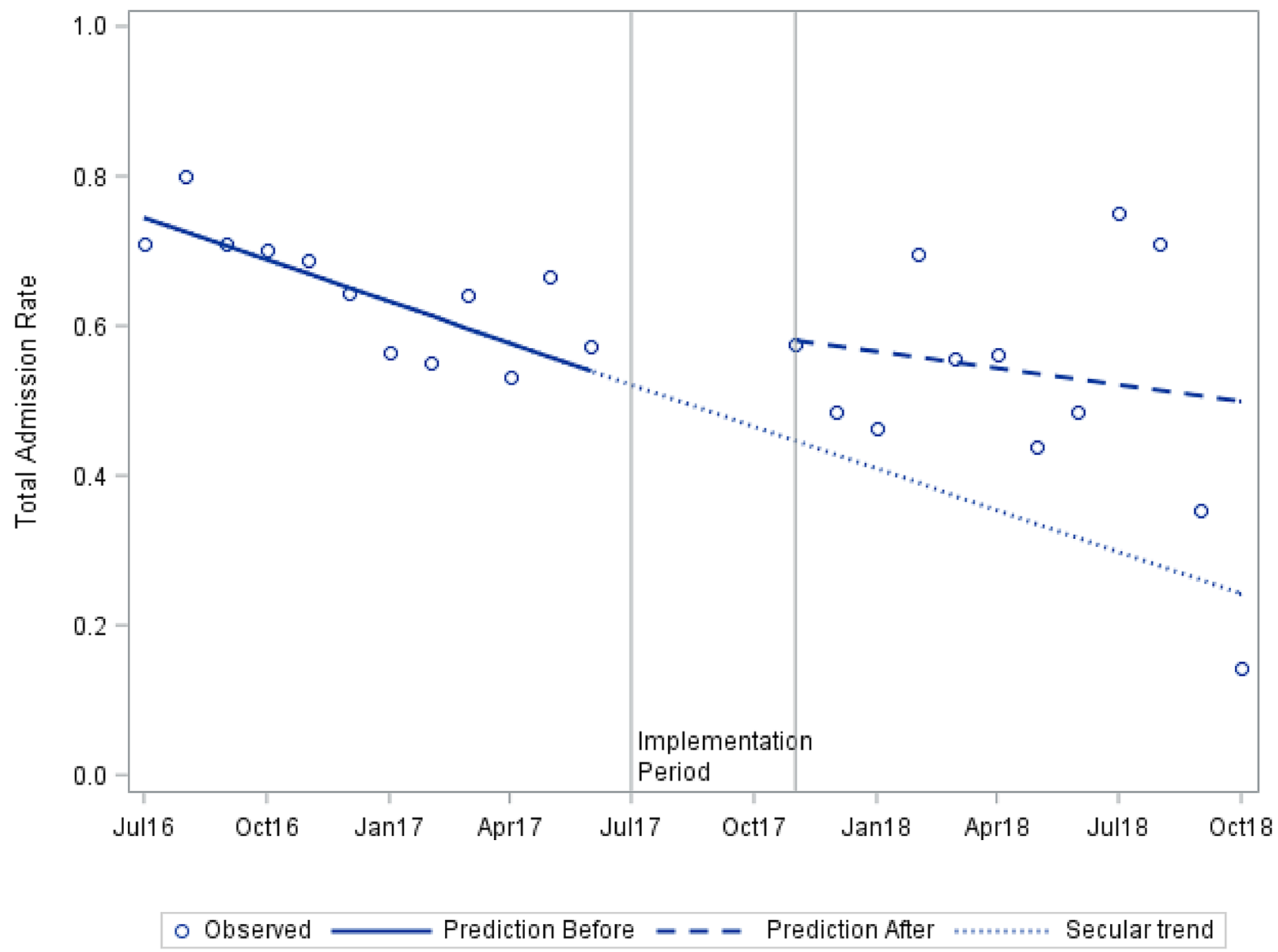

Fig. 2 Segmented autoregression analysis of total 30-days admissions by month

Table 3 Interrupted Time Series Logistic Regression Analysis of the primary outcome (30-days admissions), adjusting for the secular trend and changes in patient characteristics from before to after

\begin{tabular}{llr}
\hline & Odds ratio $(95 \% \mathrm{CI})$ & $P$ value \\
\hline Intercept & & 0.01 \\
Monthly change in admissions before & $0.93(0.87 ; 1.00)$ & 0.04 \\
Immediate change in admissions after intervention & $1.51(0.67 ; 3.38)$ & 0.32 \\
Additional monthly change after intervention & $1.04(0.95 ; 1.15)$ & 0.38 \\
Age (years) & $1.00(0.98 ; 1.01)$ & 0.67 \\
Male & $0.73(0.53 ; 1.02)$ & 0.06 \\
Serum creatinine $(\mu \mathrm{mol} / \mathrm{L})$ & $1.00(1.00 ; 1.01)$ & 0.01 \\
Valvular heart disease & $2.55(1.77 ; 3.70)$ & $<0.01$ \\
IV diuretics in ED & $2.02(1.11 ; 3.70)$ & 0.02 \\
Non-invasive ventilation in ED & $5.93(2.62 ; 13.42)$ & $<0.01$ \\
Counterfactual difference at study end (combined intercept & $2.04(0.63 ; 6.65)$ & 0.23 \\
and slope change) & & \\
\hline
\end{tabular}

hospital on the index ED visit from $57.7 \%$ in the before phase to $42 \%$ in the after phase and considering all admissions within 30 days, there was also a reduction from 65.1 to $53.5 \%$. The mortality amongst all patients was similar in the two phases $(4.5 \%$ vs $4.0 \% ; P=0.74)$.

Table 2 shows the characteristics of the main study population, patients who were discharged home from the ED. The 
mortality was similar in the two phases $(3.3 \%$ vs $1.8 \%)$ as was the proportion requiring subsequent admission (17.3\% vs $21.2 \%)$. We also noted no increase in ED re-visits (32.0\% vs $29.0 \%$ ).

The segmented regression analysis of the primary outcome (Fig. 2; Table 3) controlling for the secular trend and changes in patient characteristics over time, shows a strong pre-existing decline in admission rates $(P=0.04)$. After the introduction of the clinic, there was neither a significant immediate change $(P=0.32)$ nor a gradual change $(P=0.38)$ in the admission rates. Thus, although there was a total decrease in admission rates from the before period
Table 4 Referrals and attendance for patients discharged and referred from the ED-N (\%)
Table 5 Investigations and medication changes for discharged patients on followup-N $(\%)$

\begin{tabular}{llll}
\hline & $\begin{array}{l}\text { Before } \\
N=135\end{array}$ & $\begin{array}{l}\text { After } \\
N=202\end{array}$ & Difference (95\% CI) \\
\hline Overall follow-up attendance & $36(26.7)$ & $97(48.0)$ & $21.3(10.8 ; 30.9)$ \\
Days until seen, median (IQR) & $13(8-19)$ & $6(4-14)$ & \\
Seen within 7 days & $12(8.9)$ & $58(28.7)$ & $19.8(11.5 ; 27.4)$ \\
Number of visits & & & \\
1 & $44(32.6)$ & $88(43.6)$ & \\
$>1$ & $6(4.4)$ & $19(9.4)$ & $22.4(11.7 ; 32.5)$ \\
All specialist referrals & $64(47.4)$ & $141(69.8)$ & \\
Cardiology acute HF & - & $22(10.9)$ & \\
Internal medicine acute HF & - & $59(29.2)$ & \\
Routine cardiology & $59(43.7)$ & $64(31.7)$ & \\
Routine internal medicine & $6(4.4)$ & $2(1.0)$ & \\
All specialist attendance $(N=64: 141)$ & $24(37.5)$ & $85(60.3)$ & $22.8(8.0 ; 36.1)$ \\
Cardiology acute HF & - & $14(9.9)$ & \\
Internal medicine acute HF & - & $45(31.9)$ & \\
Routine cardiology & $20(31.3)$ & $25(17.7)$ & \\
Routine internal medicine & $4(6.3)$ & $1(0.7)$ & \\
Family doctor & & & \\
Referral & $110(81.5)$ & $119(58.9)$ & $-22.6(-31.5 ;-12.7)$ \\
Attendance $(N=110: 119)$ & $9(8.2)$ & $6(5.0)$ & $-3.2(-10.4 ; 3.5)$ \\
\hline
\end{tabular}

\begin{tabular}{llll}
\hline & $\begin{array}{l}\text { Before } \\
N=36\end{array}$ & $\begin{array}{l}\text { After } \\
N=97\end{array}$ & Difference (95\% CI) \\
\hline Investigations ordered & $14(38.9)$ & $49(50.5)$ & $11.6(-7.4 ; 28.7)$ \\
Echocardiography & $14(38.9)$ & $49(50.5)$ & \\
Stress test & $0(0)$ & $0(0)$ & \\
Computed tomography & $0(0)$ & $0(0)$ & \\
Holter & $0(0)$ & $0(0)$ & \\
Medication changes & $20(55.6)$ & $66(68.0)$ & \\
Diuretic & $14(38.9)$ & $59(60.8)$ & \\
New prescription & $3(8.3)$ & $8(8.2)$ & \\
Dose change & $11(30.6)$ & $51(52.6)$ & \\
Beta blocker & $9(25.0)$ & $13(13.4)$ & \\
New prescription & $3(8.3)$ & $3(3.1)$ & \\
Dose change & $6(16.7)$ & $10(10.3)$ & \\
ACE inhibitor & $5(13.9)$ & $9(9.3)$ & \\
New prescription & $3(8.3)$ & $4(4.1)$ & \\
Dose change & $2(5.6)$ & $5(5.2)$ & \\
Angiotensin II receptor blockers & $4(11.1)$ & $3(3.1)$ & \\
New prescription & $1(2.8)$ & $1(1.0)$ & \\
Dose change & $3(8.3)$ & $2(2.1)$ & \\
\hline
\end{tabular}


to the after period, this cannot be attributed to our intervention. The difference between the post-intervention predicted value at the end of the study and the counterfactual indicates that admissions may be higher than had the clinic not been introduced, although the confidence interval around the estimate is wide and overlaps with 1 (Odds Ratio $2.04 ; 95 \%$ CI $0.63-6.65 ; P=0.23$ ).

Table 4 shows that the proportion of patients attending a specialty clinic, amongst those referred, increased from 26.7 to $48.0 \%(P<0.01)$ and the median days to clinic decreased from 13 to 6 days $(P<0.01)$.

Table 5 and Appendix Table 1a and $\mathrm{b}$ show the investigations and medication changes that were ordered for those patients who did attend a clinic. There were no clear differences in the investigations and medications ordered, separately, at the internal medicine and cardiology clinics.

Appendix Tables 2, 3, and 4 show comparisons between discharged patients who returned and those who did not, between those with prior HF and those without, and between those who were admitted and those discharged on initial ED visit.

\section{Discussion}

\section{Interpretation}

We enrolled more than 700 patients into this patient safety project to evaluate the impact of implementing rapid access specialty clinics on the outcomes of ED patients with acute HF. While there were significant barriers to implementation, attendance at hospital specialty clinics, amongst those discharged, more than doubled. As well, the time to clinic visit declined by more than half. There was a pre-existing trend for decreasing hospital admissions before the rapid access clinics were introduced and thus, we cannot conclude that they had any impact on this outcome. Certainly, there was no increase in return visits to the ED or in 30-days mortality. We perceive that overall hospital admissions are decreasing in Canada, possibly due to a lack of inpatient beds. Hence, early access clinics are even more critical to ensure high quality safe care for the many heart failure patients discharged from the ED. Widespread use of this approach can improve acute heart failure care in Canada for ED patients not admitted to hospital.

\section{Previous studies}

Most previous evaluations of heart failure clinics focussed on chronic heart failure or patients discharged from a hospital admission rather than on ED patients. While some others demonstrated a decrease in mortality or readmissions over time $[9,11]$, a recent study failed to show any clear benefit from a transitional plan [17]. Three different systematic reviews found improved mortality for chronic heart failure patients with a variety of follow-up interventions including home visits, nurse led monitoring, and telephone follow-up but did not include the Van Spall study $[8,12,16]$. Two commentaries took opposing views on the value of heart failure clinics $[10,13]$. We could only find two studies that look at heart failure follow-up after an ED visit and both were retrospective analyses of administrative databases [14, 15]. Lee found better outcomes if patients had primary care plus cardiology follow-up within 30 days [14]. Atzema found less mortality for patients seen by a physician within 7 days but did not identify the type of physician [15].

\section{Limitations and strengths}

We believe this to be the first prospective interventional study to evaluate rapid follow-up for acute heart failure patients discharged from the ED. This pragmatic study required the interdisciplinary coordination of emergency medicine, internal medicine, and cardiology. Overall the compliance for referrals by emergency physicians was very good. Internal medicine and cardiology created rapid-access clinics but there were some challenges with occasional clinic shutdowns or wait times longer than the target of $72 \mathrm{~h}$. Nevertheless, the median time to clinic visit was 6 days. We did not have sufficient power to evaluate impact on mortality. The analyses of total admissions were complex but did not show a decline attributable to the clinic. While we had some patients who had no appointment scheduled, no patients were lost to follow-up for the outcomes of 30-days admissions or attendance at a specialty clinic. We limited our follow-up period to 30 days so may not have identified longer-term implications. There may be concerns about enrolment bias in either the before or after periods, but we do not believe this is the case as all patients were enrolled by the same health records review procedures in both periods. We did not have the resources to telephone the patients that had no hospital visits in the 30-days study period.

\section{Clinical implications}

ED disposition decisions are difficult for physicians dealing with acute heart failure patients. Some patients clearly need hospital admission due to the severity of their acute episode. Many other patients improve rapidly with diuresis and may be well enough to go home. Prior research has focussed on risk scales to identify patients at low medical risk of short-term serious outcomes $[5,6,18]$. There are, however, other factors for clinicians to consider such 
as the degree of home support the patient may have and the potential of optimizing medical therapy, for example increasing the dosage of diuretics. A major concern is that patients may not have early access to either a family doctor or a specialist to re-evaluate the patient and consider further investigations and treatments. Assurance that rapid follow-up is available may tip the balance towards ED discharge for acute heart failure patients. This would benefit both the patient as well as a health care system that often lacks available hospital beds.

Our study highlights that, even with the availability of rapid-access clinics, only $45 \%$ of patients discharged from the ED attended. Either there were system failures with no appointments made or the patients declined the opportunity to book or attend an appointment.

\section{Research implications}

Larger scale multicentre studies are required to clarify the role of rapid-access clinics on overall admissions as well as mortality. Such studies should also assess the feasibility of establishing rapid follow-up for acute heart failure patients in non-academic and smaller hospitals.

\section{Conclusion}

We implemented rapid-access, dedicated acute heart failure clinics for patients discharged from the ED. This led to considerably increased access to specialist care and much reduced follow-up times, without an increase in return ED visits or mortality. Widespread use of this rapid-access approach to a specialist may improve care for the many acute heart failure patients in the ED who are discharged home rather than admitted to hospital.

Acknowledgements We gratefully acknowledge Angela Marcantonio and Connor Sheehan from the Ottawa Hospital Research Institute for their contributions to this project. We are very grateful to the emergency department physicians, nurses and respiratory therapists for their invaluable and tireless assistance. We would also like to acknowledge the internal medicine and cardiology teams whose efforts made the implementation of the rapid-access specialty clinics a success.

Author contributions IGS and JJP conceived the idea, prepared the manuscript, and secured research funding. CMC managed the budget, contracts, and personnel. LM and HC managed the rapid access specialty clinics. JB coordinated the study and supervised data collection. JB and ELB supervised the enrollment of patients and management of data. MT and MJN did the statistical analyses. All authors supervised the study and data collection or drafted the manuscript and contributed to its revision, and all approved the final version. IGS is guarantor.

Funding This study was funded by The Ottawa Hospital Academic Medical Organization (TOHAMO). JJP is supported by an Award from the Heart and Stroke Foundation of Ontario.

\section{Compliance with ethical standards}

Conflict of interest The authors declare that they have no competing interests.

\section{References}

1. Yancy CW, Jessup M, Bozkurt B, et al. 2013 ACCF/AHA guideline for the management of heart failure: executive summary: a report of the American College of Cardiology Foundation/American Heart Association Task Force on practice guidelines. J Am Coll Cardiol. 2014;62(16):1495-539.

2. Ponikowski P, Voors AA, Anker SD, et al. 2016 ESC Guidelines for the diagnosis and treatment of acute and chronic heart failure: the task force for the diagnosis and treatment of acute and chronic heart failure of the European Society of Cardiology (ESC)Developed with the special contribution of the Heart Failure Association (HFA) of the ESC. Eur Heart J. 2016;37(27):2129-200. https ://doi.org/10.1093/eurheartj/ehw128.

3. Ezekowitz JA, O'Meara E, McDonald MA, et al. 2017 Comprehensive update of the canadian cardiovascular society guidelines for the management of heart failure. Can J Cardiol. 2017;33(11):1342-433. https://doi.org/10.1016/j. cjca.2017.08.022 ([published Online First: 2017/11/08]).

4. McDonald MA, Ashley EA, Fedak PWM, et al. Mind the gap: current challenges and future state of heart failure care. Can J Cardiol. 2017;33(11):1434-49. https://doi.org/10.1016/j.cjca.2017.08.023 ([published Online First: 2017/11/08]).

5. Stiell IG, Clement CM, Brison RJ, et al. A risk scoring system to identify emergency department patients with heart failure at high risk for serious adverse events. Acad Emerg Med. 2013;20(1):17-26.

6. Stiell IG, Perry JJ, Clement CM, et al. Prospective and explicit clinical validation of the ottawa heart failure risk scale, with and without use of quantitative NT-proBNP. Acad Emerg Med. 2017;24(3):316-27. https://doi.org/10.1111/acem.13141.

7. Eastwood CA, Howlett JG, King-Shier KM, et al. Determinants of early readmission after hospitalization for heart failure. Can J Cardiol. 2014;30(6):612-8.

8. Takeda A, Taylor SJ, Taylor RS, et al. Clinical service organisation for heart failure. Cochrane Database Syst Rev. 2012. https:// doi.org/10.1002/14651858.CD002752.pub3.

9. Ezekowitz JA, van WC, Mcalister FA, et al. Impact of specialist follow-up in outpatients with congestive heart failure. CMAJ. 2005;172(2):189-94. https://doi.org/10.1503/cmaj.1032017.

10. Howlett JG. Specialist heart failure clinics must evolve to stay relevant. Can J Cardiol. 2014;30(3):276-80.

11. Wijeysundera HC, Trubiani G, Wang X, et al. A population-based study to evaluate the effectiveness of multidisciplinary heart failure clinics and identify important service components. Circ Heart Fail. 2013;6(1):68-75.

12. Feltner C, Jones CD, Cene CW, et al. Transitional care interventions to prevent readmissions for persons with heart failure: a systematic review and meta-analysis. Ann Intern Med. 2014;160(11):774-84.

13. Jaarsma T, Stromberg A. Heart failure clinics are still useful (more than ever?). Can J Cardiol. 2014;30(3):272-5.

14. Lee DS, Stukel TA, Austin PC, et al. Improved outcomes with early collaborative care of ambulatory heart failure patients discharged from the emergency department. Circulation. 2010;122(18):1806-14.

15. Atzema CL, Austin PC, Yu B, et al. Effect of early physician follow-up on mortality and subsequent hospital admissions 
after emergency care for heart failure: a retrospective cohort study. CMAJ. 2018;190(50):E1468-77. https://doi.org/10.1503/ cmaj.180786 ([published Online First: 2018/12/19]).

16. Gandhi S, Mosleh W, Sharma UC, et al. Multidisciplinary heart failure clinics are associated with lower heart failure hospitalization and mortality: systematic review and meta-analysis. Can J Cardiol. 2017;33(10):1237-44. https://doi.org/10.1016/j. cjca.2017.05.011 ([published Online First: 2017/08/16]).
17. Van Spall HGC, Lee SF, Xie F, et al. Effect of patient-centered transitional care services on clinical outcomes in patients hospitalized for heart failure: the PACT-HF randomized clinical trial. JAMA. 2019;321(8):753-61. https://doi.org/10.1001/ jama.2019.0710 ([published Online First: 2019/02/27]).

18. Lee DS, Stitt A, Austin PC, et al. Prediction of heart failure mortality in emergent care: a cohort study. Ann Intern Med. 2012;156(11):767-261. 